\section{Jenseits des Nationalen}

\section{Der 'Kolor als identitätstopographierende (Tanz-)Figur in den südslawischen Romantiken}

Warum ist die Schnittstelle Literatur, Musikalität und Topographie im Kontext der südslawischen kollektiven Identitätsdiskurse interessant? Ich nähere mich hier einer im südslawischen Raum symptomatischen (getanzten) Identitätsfigur - dem Reigen (`Kolo`) - zum Zeitpunkt ihrer Aktualisierung im literarischen Umfeld der Romantik. Als Referenzepochen im Zeitraum des >Narodni preporod ${ }^{1}$ stehen die südslawischen romantischen Literaturen oft in vielfältigen Bezügen zur Konstruktion von nationalen Identitäten. Gleichzeitig zeugen bereits ihre je nach Bezugsphase und (trans)lokalem Schwerpunkt unterschiedlichen literaturhistoriographischen Bezeichnungen von einer pluralen Literaturszene, deren (trans)nationale und (gesamt)europäische Einordnungen bis heute Gegenstand von

1 Die entsprechenden Begriffe in den westlichen Sprachen 'Nationale Wiedergeburt ‘, >National Awakening ‘, >Renaissance nationale $<$ - enthalten m.E. insofern einen problematischen Aspekt, als sie das slawische >narodni $<$ (vgl. $>$ narodowe odrodzenie - poln., `národné obrodenie - slovak., `národní obrození</>národní vzkříššní< - tsch.) durch den Begriff des Nationalen ersetzen und damit die im slawischen 'narodni< zu diesem Zeitpunkt nur schwer auszudifferenzierende Verwischung der Grenzen zwischen Volk und Nation unberücksichtigt lassen.
Der Artikel wirft ein Licht auf Konstruktionsstrategien von kollektiven Identitäten am Schnittpunkt von Musik, Literatur und deren Verhandlungen von topographischen Prozessen. Der 'Kolor, der typische südslavische Reigen, wurde in der Zeit der Romantik zu einem Gegenstand intensiver literarischer Aktualisierung. In der Betrachtung einiger 'Kolor-Gedichte werden Formen und Funktionen von literarischem Mapping von Volkskultur diskutiert, literarische Reflexionen zur geopoetischen und geopolitischen Erfindung der Nation (bzw. des Volks) sowie die dabei stattfindenden Verflechtungen von musikalischen und literarischen Wirkungsweisen. Als Fluchtpunkt ist die Analyse von der Absicht geleitet, einige Konturen von südslawischen Identitätskonstruktionen jenseits des Nationalen nachzuzeichnen. 
Diskussionen darstellen. ${ }^{2}$ Wenn auch die Involvierung dieser Literatur der mittleren Jahrzehnte des 19. Jahrhunderts in die Formung kollektiver Identitäten - nicht zuletzt über das durch die Romantik intensivierte Interesse am (eigenen) Volk und seiner Kultur - unbestritten ist, dann ist gerade die Frage, welche Nation dabei imaginiert wurde und wie literarische oder literarisierte Nationalität (`narodnost `) zu fassen ist, eine komplizierte. ${ }^{3}$

Auf diese Fragestellungen vermögen die literarischen Modellierungen des $>$ Kolo< einige Perspektiven zu eröffnen. Nicht nur wirft diese (Tanz-) Figur ein Licht auf die den südslawischen Literaturen gemeinsame volkskulturelle Basis, sie wurde gerade auch über ihre topographierende Wirkung nachhaltig in Prozesse kollektiver Identitätsreflexion involviert. Ihre Betrachtung lässt deshalb Formen und Funktionen der literarischen Aktualisierung von volkskulturellen (musikalischen) Semiotiken nachvollziehen. Die dabei stattfindende Auseinandersetzung mit geopoetischen und geopolitischen Visionen der Nation bzw. des Volks findet so gerade über die Verflechtung von musikalischen und literarischen Topographien zu spezifischen Sinndimensionen.

Was ist mit identitätstopographierender Literatur gemeint? Von Janko Draškovićs »Mi usried Europi ležimo, nama se prieti istok i zapad « über Ivan Kukuljevićs »Gdje je slavska domovina? «, Petar Petrović Njegošs »Ponosita lovćenska planino« oder Petar Preradovićs »Od Stambula grada do Kotora « bis zu Laza Kostićs Jadranski prometej ${ }^{4}$ bildet die TopoGraphierung, die räumliche Er-Schreibung, immer wieder ein zentrales Verfahren der Aushandlung (kollektiver) identitätsstiftender Ordnung in dieser Zeit. Literarische Texte können selbst in Verfahren involviert sein, topographische Praktiken auszuagieren - oder diese zu reflektieren. ${ }^{5}$ Dabei

2 Vgl. die Epochenbezeichnungen `(narodni) preporod` (Nationale Wiedergeburt), >ilirizam^ (Illyrismus), >(pred)romantizam`(Vor-Romantik), speriod integracije heterogenih stilova (Periode der Integration heterogener Stile), >omladinska književnost ‘ (Literatur der Omladina) u.ä. Vgl. zur Aufarbeitung dieser Bezeichnungs- und Konzeptvielfalt im kroatischen Kontext: Coha: Medij, kultura, nacija und im serbischen Kontext: Jovičević: Prostori srpskog predromantizma. Für eine bosnisch geprägte Auseinandersetzung mit dem Begriff der südslawischen Romantik empfiehlt sich Rizvić: Interpretacije iz romantizma I $u$. II.

3 Vgl. hierzu die Arbeiten der Komparatisten-Gruppe Komparativno proučavanje južnoslavenskih književnosti, z.B. Živančević: Tipologija hrvatskog i srpskog romantizma. Einen guten Überblick aus postjugoslawischer Perspektive bietet Lacko Vidulić: Jugoslawische Literatur.

4 Vgl. Drašković: Disertatia iliti razgovor (1832): Wir liegen inmitten Europas, uns droht der Westen und der Osten « (Übersetzung hier und überall, wenn nicht anders angegeben: A.H.); Kukuljević Sakcinski: Slavjanska domovina (1841): »Wo ist die slavische Heimat? «; Petrović Njegoš: Lovéenu (1847): „Stolzer Lovćen-Berg«; Preradović: Rodu o jeziku (1860): »Von der Stadt Istanbul bis nach Kotor «; Kostić: Jadranski Prometej (1870): »Adriatischer Prometheus«. Vgl. Frank: Geokulturologie - Geopoetik, S. 31. 
verwischen sich gerade in der Zeit der Romantik oft die Grenzen zwischen geopoetischen und geopolitischen Verortungen der Nation bzw. des Volks.

\section{Vom Tanz zum Volk zum Raum: Topographische Dehierarchisierung}

Graf Janko Drašković (1770-1856), der in der ersten Hälfte des 19. Jahrhunderts u.a. als (Mit)Initiator der >Matica ilirska zu den wichtigen Organisatoren des kulturpolitischen Lebens in Zagreb gehörte, organisierte 1818 anlässlich des Besuchs von Kaiser Franz I. in Zagreb einen Reigen und führte ihn selbst an. ${ }^{6}$ Als Tänzer und Sänger traten keine Bauern oder andere Menschen aus dem reinfachen Volk auf, sondern Vertreter einer urbanen Elite in volkstümlichen Verkleidungen. Die vorgetragenen Volkslieder hatte der Graf persönlich verfasst. ${ }^{7}$ Dem zu dieser Zeit in Europa verbreiteten Phänomen der Neu(re)konstruktion von Volkstänzen für die Eliten kann hier nicht weiter nachgegangen werden; ${ }^{8}$ Draškovićs Intervention ist aber bedeutsam vor dem Hintergrund, dass eine der ersten in den einschlägigen Kanons der südslawischen Romantiken enthaltenen `Kolo<-Bearbeitungen ebenfalls von ihm stammt: Es ist das Gedicht Poskočnica, das 1835 in Ljudevit Gajs zu diesem Zeitpunkt noch »Danicza Horvatzka, Slavonzka y Dalmatinzka" genannter Zeitschrift erschien.

Der Titel, Poskočnica, rekurriert auf eine Form des Reigens, die mit Gesang einhergeht: Die sposkočicaく ist dabei ein textimprovisierender `Kolo‘, der sich durch relative Kürze, tendenzielle inhaltliche Leichtigkeit sowie durch einen spielerischen Charakter und ein erhöhtes Tempo von anderen Tanz- und Liedformen unterscheidet. ${ }^{9}$ Draškovićs Gedicht beginnt mit einem >Kolo<, der in >Horvatska und >Ilirička getanzt werde: »Kolo igra u Horvatskom,/ Njim se pleše v Iliričkom. ${ }^{10}$ Auf diesen Parallelismus, mit dem der Autor den Übergang von seiner `horvatisch`-kajkavischen zu seiner illyrisch-štokavischen Phase markiert, erfolgt in der zweiten Strophe der Sprung vom Tanz zur Gesellschaft - »Kada društvo igra kolo,/ Svi se vrte naokolo. ${ }^{11}$-, worauf ab der dritten Strophe die konkrete Ebene des Reigens verlassen und der >Kolo< als Gesellschaftsform mehr und mehr in symbolische Bedeutungskontexte überführt wird: Als »Ringwunder«

7 Vgl. Dubinskas: Performing Slavonian Folklore, S. $28 \mathrm{f}$.

8 Vgl. Shay: $L A D O$, S. $263 f$.

9 Vgl. Mladenović: Kolo u južnih Slovena, S. 152f.

10 Drašković: Poskočnica. (»Es tanzt ein kolo in Kroatien, man tanzt ihn auch in Illyrien.«)

11 Ebd. (»Wenn die Gesellschaft einen kolo tanzt, drehen sich alle rundherum.«) 
und »Bruderschaft« wird er zum unendlichen »Kranz«, in welchem kein »Unglaube« sei, und zum »Heiligen Feuer», das alle vernichtet, die »falsch « seien. Ein Feuer »von göttlicher Farbe«, bereit den »Verräter « zu verdammen. ${ }^{12}$ Wo zunächst die Gesellschaft - tanzend - selbst den `Kolo < bildete, richtet sich dieser, auf einmal selbständig geworden, gegen sie - im Falle des Unglaubens oder des Verrats. Draškovićs Text lässt nachvollziehen, wie die >Kolo<-Figur von konkreten auf symbolische Ebenen springend eine nahezu allegorische Verkettung zwischen dem musikalischen Ereignis und einer Identitätstopographie erwirken kann, deren poetisch-symbolische und politische Sinndimensionen nur schwer eindeutig voneinander zu trennen sind. Es ist eine Verkettung in der Form eines >mise-en-abyme`, eines sich fortsetzenden Integrierens verschiedener identitätskonstruierender Ebenen in jeweils nächst(weiter)e - geographische (Horvatska - Ilirička), mediale (Tanz, Gesang, Literatur) und gesellschaftliche (Kultur, Religion, Ethik) -, wobei diese Reihung gleichzeitig auch in umgekehrter Richtung verläuft: Letztlich werden all diese Ebenen auf ein Element, den `Kolo‘, zurückgeführt und auf Kosten ihrer polymorphen Bezugs- und Funktionsstrukturen vereinheitlichend perspektiviert bzw. ihm untergeordnet.

Die im Text ausgelegte illyrische Identitätsperspektive wird durch die musikalische Dimension des Gedichtes einerseits gestützt, indem sie sich im regelkonformen rhythmischen Gewand des trans-südslawischen (bzw.

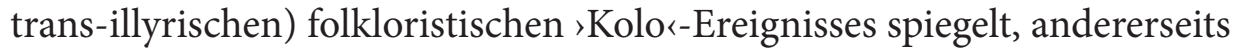
dennoch latent durchkreuzt: Der im Kontext der Hinwendung zur Volkskultur (aber auch zur Renaissance- und Barockliteratur Dalmatiens) populäre `osmerac` (Achtsilbler), welcher dem Text einen sorglos anmutenden, hüpfenden Rhythmus verleiht, sowie der Titel, Poskočnica, der ebenfalls einen leichtfüßigen Textinhalt suggeriert, setzen zur Inhaltsschwere einen Kontrapunkt und akzentuieren - gerade vor dem Hintergrund des zu diesem Zeitpunkt effektiv populären Tanz- und Verkleidungsspiels des `Kolo $<-$ den Eindruck des Spielerischen, Inszenierten und Ephemeren. Davon zeugt letztlich auch die zweite Strophe mit einem potentiellen Relativierungshebel: »Kada društvo igra kolo,/ Svi se vrte naokolo. «Wenn die Gesellschaft aber gerade nicht tanzt, dann dreht sie sich auch nicht in oder entlang dieser spezifisch vereinheitlichenden, (ver)bindenden Struktur. Erst das (literarische) Ereignis des >Kolo < bringt diese Identitätstopographie(rung) hervor.

12 Vgl. »To jest pelda kolobara,/ Kažuć ljubav nam kotara.// Pobratimstvo kano vijenac,/ Kaže da mu nije konac.// Da nevjeri nima mesta,/ Za lošoga da je cesta.// Kolo svigdi oblje biva,/ Sveta vatra iz njeg siva.// Ona gleda podaviti,/ Svakog krivog pogaziti.// Božja mu je boja lice,/ Proklinjanje izdajice.« (ebd.) 
Ein weiterer 〉Kolo<-Text, welcher die illyrische Linie, die bei Drašković angelegt ist, gerade räumlich im Detail ausdekliniert und somit eine der prägenden >Kolo<-Topographien der südslawischen Romantiken ausgestaltet, ist das Gedicht von Pavao Štoos (1806-1862), Poziv u kolo ilirsko (Aufruf in den illyrischen Reigen), das 1840 in Ljudevit Gajs nun »Danica ilirska « genannten Zeitschrift erschien. Der Titel referiert erneut prominent auf die Reigen-Kultur - allerdings mittels einer sekundären Bezugnahme: Der >kolo< übernimmt im Titel nun die Funktion des Objekts. In der hier noch unmittelbareren Verknüpfung des `Kolo` mit der südslawischen Identitätsfigur des Illyrischen ist die Strategie erkennbar, dem Illyrischen durch seine Topographierung als $>$ Kolo $<$ etwas (transnational) Volksnahes, Ursprüngliches und Natürliches zu verleihen.

Im Refrain, mit dem das Gedicht einsetzt (»U ilirsko kolo milo/ Vratite se srodni puci,/ Što su stari gvožđem bili,/ Nek su duhom sad unuci!«), ${ }^{13}$ sind zwei Integrationsstrategien enthalten: die Anordnung der illyrischen >Völker ‘ als `verwandte und die Bestimmung einer ihnen allen gemeinsamen, neuen Charakteristik. Durch die Betonung des >lieblichen`Charakters des Reigens wird sein nichtmartialischer Zweck betont; der abermals eingesetzte `osmerac betont ebenfalls eine leichtfüßige, spielerische Geartetheit dieses Reigens. Und dennoch: Der Behauptung der Natürlichkeit des `Kolo< sowie der illyrischen Verwandtschaft steht die Setzung einer `neuen` oder neu ausgerichteten Gemeinschaft spannungsgenerierend gegenüber und offenbart ein Konstruktions- oder zumindest Evolutionsmoment, welches die natürliche Gegebenheit der Dinge überlagert.

Im Anschluss an den Refrain werden verschiedene Regionen/Völker innerhalb des illyrischen Raums aufgerufen und jeweils zweifach in den »kolo ilirsko« eingegliedert: über ein nur ihnen oder ihnen besonders eigenes Merkmal sowie über ein auch ihnen eigenes Merkmal. Damit wird ausdrücklich eine innere Diversität betont, während die Elemente gleichzeitig der im Refrain bekundeten, übergeordneten Topographie zugehörig erklärt werden:

I Slavonci, slave sini,

Ki ste uvijek krepki, možni

$\mathrm{Na}$ čest jednoj domovini

Sa Hrvati bili složni.

[...]

I vi Kranjci, tak nazvani

Od ilirske negda krajne,

13 Štoos: Poziv u kolo ilirsko, S. 251 (»In den lieblichen illyrischen Reigen/ Kehrt zurück, ihr verwandten Völker,/ Was die Alten durch Eisen erreichten,/ sollen die Enkel nun mit dem Geist.«) 
Ki ste starom Rimu znani

Rad desnice vaše sjajne! ${ }^{14}$

Im Prozess der Einordnung der Völker in die illyrische Topographie, wie er im Verlauf des Textes vorgenommen wird, liegt ein weiteres spannungskreierendes Moment. Die dreifache Wiederholung des Refrains lässt auf eine Unterteilung des Textes in drei Teile schließen, welche verschiedene und - was ihre Integration in den illyrischen Reigen betrifft - verschieden behandelte Gruppen ordnet: Auf die erste Gruppe (Hrvati, Slavonci, Dalmatini, Dubrovčani, Istrijanci, Korušci, Kranjci, Štajerci) folgt nach der Wiederholung des Refrains die zweite, teilweise etwas umständlicher referierte Gruppe: Međimurci und Podunavci (allerdings nicht mit diesen Regionymen ausgedrückt, sondern mit einer kartographischen Absteckung, nämlich »Među Murom, na Dunavu/ Što stanuje, k nam nek stupa $«),{ }^{15}$ weiter die Bačvani, Banaćani und Srblji, die "Söhne der bosnischen Gemeinschaft» (»Od bosanske sini družbe«) und die Hercegovci, Crnogorci, Bugari. Nach dem daraufhin zum letzten Mal wiederholten Refrain wird im dritten Teil der `kolo ilirsko in eine Reihe weiterer Reigen (Russland, Polen, Tschechien) gestellt, die zusammen den slawischen Reigen bilden - hier folgt Štoos dem Erkenntnisstand seiner Gesinnungsgenossen, ${ }^{16}$ mit der Pointe nur, dass die vier Räder ( $>$ Kolo $<$ bedeutet auch $\left.>\operatorname{Rad}{ }^{17}\right)$ am Schluss tatsächlich zu einem Wagen mutieren, auf dem »unsere Mutter « (Slava) ins Glück »fahre«. ${ }^{18}$

Die erste Gruppe steckt augenscheinlich den heutigen kroatisch-slovenischen Raum ab und damit jenen Teil Illyriens, der dem nördlich von Zagreb geborenen Autor, der seine ersten Gedichte auf Kajkavisch verfasste,

14 Ebd., S. 251 (»Und ihr Slavonier, Söhne des Ruhms,/ Die ihr immer stark und mächtig,/ Zur Ehre der einen Heimat/ Mit den Kroaten einig wart. [...] Und ihr Krainer, so genannt/ nach einer ehemaligen illyrischen Region [krajina],/ euch kannte das alte Rom/ dank der Arbeit eurer glänzenden Faust.«)

15 Ebd., S. 252 (»Im Zwischenmurgebiet, an der Donau,/ wer dort wohnt, trete zu uns«).

16 Vgl. Šafáriks Geschichte der slawischen Sprache und Literatur nach allen Mundarten (1826) oder Kollárs O literární vzájemnosti mezi kmeny a náréčími slavskými (1831-36), die ähnliche Vorstellungen der Unterteilung der Slaven in vier `Stämme`, >Mundarten` oder `Zweige ‘ enthalten.

17 Laut dem Wörterbuch der jugoslawischen Akademie sind im Wortfeld >Kolo< zwei Hauptbedeutungen vorhanden, die zunächst über den `Kolo< als Tanz hinausgehen: `rota‘, das Rad, und >circulus`, der Kreis. Vgl. Rječnik hrvatskoga ili srpskoga jezika, S. 207-211.

18 Vgl. Štoos: Poziv u kolo ilirsko, S. 253 (Kursivsetzungen i.O., ebenso die Häufung der Ausrufezeichen): »Prvo kolo Ruska ima,/ Drugo Poljska, Česka treće,/ A četvrto nek uzima/ Duh ilirski uvijek veće.// Na tih kolih nek se stara/ Naša majka naprijed vozi,/ Da nam k sreći put otvara!/ U to ime bog pomozi!!!« (»Den ersten kolo hat Russland,/ den zweiten Polen, Tschechien den dritten,/ Und den vierten soll übernehmen/ der illyrische Geist immer mehr.// Auf diesem Wagen soll unsere alte/ Mutter vorwärts fahren,/ Dass sie zum Glück den Weg uns eröffne!/ Dabei helfe Gott!!!«) 
sicherlich am nächsten lag. Im weitesten Sinne auf der klangtopographierenden Ebene ist - neben der Reihenfolge und damit auch implizit markierten Hierarchie innerhalb der ersten Gruppe (die >Hrvati< stehen wohl nicht von ungefähr ganz zuerst) - am `Textplatz‘, der den einzelnen Regionen zugeteilt wird, ablesbar, für wie wichtig sie der Autor jeweils hält, sodass zum Beispiel neben den Dalmatinern, die eine ganze Strophe erhalten, die Istrier zwar erwähnt werden, sich `ihre`Strophe indes mit den Ragusanern und Kärntnern teilen müssen.

Die zweite Gruppe umfasst jene Regionen, deren Integration in den illyrischen `Kolo offenbar mehr Aufmerksamkeit benötigt: Ihnen wird für ihr allfälliges Mithalten gedankt (»Bila vam za ljubav hvala!«) und, wie v.a. im Fall der `Srblji $`$, deutlich mehr Platz zugeteilt als den anderen (vier Strophen!). Ist diese Texttopographie schlicht der (vorgestellten) Volkstopographie angepasst (stellen die Serben ja die 'größte Gruppe innerhalb der illyrischen Völker dar, wie bereits Gaj festgehalten hatte)? ${ }^{19}$ Auffällig ist auf jeden Fall, dass bei den Serben mit Ausnahme der Sprache nicht mittels gemeinsamer Traditionen oder Eigenschaften, sondern vernunftbezogen argumentiert wird: »Znajte da je slava veća/ S više braće braćom biti!// Više očî vidi više,/ Više mislî više smatra,/ Više rukâ već napiše,/ S više iskar biva vatra. $\ll^{20}$

Für die Qualifizierung der Zugehörigkeit zum illyrischen `Koloく können also unterschiedliche Argumentationskontexte eingesetzt werden; die illyrische Gemeinschaft entpuppt sich - bei aller Rückbindung an die ihnen gemeinsame volkskulturelle Ursprünglichkeit und Natürlichkeit - als eine angepasste und gemachte. Während im dritten Teil die Eingliederung des illyrischen in den sallslawischen Reigen` ganz ohne argumentativen $\mathrm{Zu}$ satzaufwand erfolgt (ebenso behände wie die Mutation der Tanzenden in ein Fahrzeug), unterscheiden sich der erste und der zweite Teil nicht nur in Bezug auf den ihnen zugeteilten Textraum, sondern auch in Bezug auf die Argumentationsebenen und -intensität, anhand derer ihre Zugehörigkeit zum Illyrischen verhandelt wird, deutlich voneinander.

Als unhintergehbare Größe setzt der Text Regionen, wobei engflächige Gegenden wie Međimurje gleichberechtigt neben größeren ethnischen Komplexen wie die >Hrvati oder `Srblji zu stehen kommen. Das Gefüge der Beziehungen zwischen den Regionen, das verbirgt der Text keineswegs, ist

20 Štoos: Poziv u kolo ilirsko, S. 252 (»Wisset, dass der Ruhm größer ist/ mit mehr Brüdern verbrüdert zu sein!// Mehr Augen sehen mehr,/ Mehr Gedanken verstehen mehr,/ Mehr Hände schreiben mehr,/ Von mehr Funken entzündet sich das Feuer.«) 
aber eine Frage der Topographierung (und nicht der Topographie), d.h. der Argumentation und Aushandlung. Dennoch bestimmt der Text die durch die `Kolo`-Form ins Horizontale, Ahierarchische neigende Zusammenfügung der einzelnen Regionen als einzig gangbare Möglichkeit: Nur ein so geordneter `Kolo<, hier als ein austariertes und von Gott behütetes Fahrzeug, fährt in Fortschritt und Glück, und es ist auch kein relativierendes ‘kada (`wenn`) mehr vorhanden. Im Unterschied zu Drašković eignen diesem `Kolo< keine Züge einer strafenden `Zentralmacht $<$ S Štoos dehierarchisiert und dezentralisiert den illyrischen Reigen gänzlich, wenn auch seine innere Organisation bestehenden Hierarchien verpflichtet bleibt, indem er sie reproduziert (Beispiel kroatische Küstenregionen) oder argumentierend ausgleicht (Beispiel Serben).

Ebenfalls im Unterschied zu Drašković kommt in Poziv u kolo ilirsko der Tanz als solcher zugunsten einer gänzlich vollzogenen Metaphorisierung nicht mehr vor. Die musikalische Ausarbeitung führt aber zum ethnochoreographischen Phänomen zurück und wirft im Kontext der zu dieser Zeit drängenden Frage nach dem Verhältnis der Volkspoesie oder -epik zur romantischen (individuellen oder formflexiblen) Kunstpoesie ${ }^{21}$ ein spezifisches Licht auf die Klangform des `Kolo<. Dies lässt sich an Pavao Štoos' - nach einschlägigen Kanonisierungen - zweitem `Hauptwerkı verdeutlichen, das ebenfalls 1835 in der »Danica « erschien. Es ist das Gedicht Kip domovine vu početku leta $1831,{ }^{22}$ welches eine aus der Perspektive eines in der Nacht umherwandernden lyrischen Ichs gegebene triste Vision eines Heimatlandes enthält, das - sich seiner selbst wenig bewusst - im Dunkeln liegt. Der im Vergleich deutlich längere Text kommt praktisch ohne Strophenbildung aus. Zwar werden pro Zeile zweifach Daktylen und Jamben alteriert, von diesem Rhythmus wird aber, gleichsam einem natürlich holprigen Sprachfluss folgend, oft abgewichen. ${ }^{23} \mathrm{Im}$ Vergleich dazu stellt Poziv $u$ kolo ilirsko in seinem Korsett des vierzeilig strophierten $>$ osmerac $\prec$ nicht nur, was die in ihm ausgelegte kollektive Identitätstopographie betrifft, sondern auch hinsichtlich der Form dieses literarisch adaptieren `Kolo $<$ ein deutlich erkennbares Moment der Konstruktivität aus, welches zur >natürlichen Ursprünglichkeit` der volkskulturell gegebenen (Klang)Topographie einen kaum aufgelösten Spannungsbogen bildet.

21 Vgl. dazu etwa: Lauer: Volksepik und Kunstepik.

22 So sind z.B. in der zweibändigen Ausgabe zum Hrvatski narodni preporod von 1965 aus der Reihe Pet stoljeća hrvatske književnosti von Štoos (nur) genau diese beiden Texte enthalten.

23 Vgl. z.B. »Anda vu morje vre vekivečno/ Jedno nam leto kapnulo srečno!/ Najmre kad vre nit cveta v dolici,/ Nit več zelenog lista v gorici,/ Nit bi gde videt z grozdekom trsa,/ Nit poljodelcu odprta prsa; (Štoos: Kip domovine, S. 245) 


\section{...und zum Tanz zurück: Topographisch-musikalische Suspension}

Während die ersten beiden Texte sprachlich-diskursive und musikalische Topographierungen dergestalt nah aneinander heranführen, ist im dritten hier zu betrachtenden Beispiel ihre nahezu gänzliche Verschmelzung zu beobachten. Es handelt sich, auch was die klangliche Durchwirkung betrifft, um den einschlägigsten >Kolo<-Text der südslawischen Romantik: Đački rastanak, ein Text, den Branko Radičević (1824-1853) 1844 im Rückblick auf seine Gymnasialzeit schrieb. ${ }^{24}$ Teile dieses Gedichts, wie das beinahe metatextuelle »Коло, коло, наоколо, виловито, пла'овито, наплетено, навезено, окићено, зачињено! «, ${ }^{25}$ sind bis heute vielen Sprachkundigen im Ohr, das Textmaterial erfuhr auch mehrfache Vertonungen und illustrative Bearbeitungen.

Đački rastanak, über 700 Zeilen lang, ist formal komplexer als die bisher analysierten Gedichte: Es weist eine geschichtete Text- und Klangstruktur auf, die inhaltlich durch eine Verkettung von Erinnerungsbildern des lyrischen Ichs geleitet wird, welches sich von seiner Jugend und gleichzeitig von seinen Heimatstätten verabschiedet. Betrachtet man das Poem aus der Perspektive seiner `Kolo<-Bearbeitung, so legt sich der Fokus auf zwei Teile des Textes, die in ihren formalen und inhaltlichen Reminiszenzen an die Art der Volksreigen als eingeschobene `Kolo < betrachtet werden können. Die Erforschung der Manuskripte hat auch gezeigt, dass zumindest der zweite >Kolo< erst später in den Text eingefügt wurde. ${ }^{26} \mathrm{Ihr}$ Eingefügtsein manifestiert sich indes bereits in einem eindeutigen Rhythmuswechsel: Der Gesamttext ist relativ durchgehend im >desetarac « gehalten (obwohl an einigen Stellen der syllabische Vers zugunsten einer Klang- oder Sprachnähe aufgegeben wird), derweil die beiden Reigen sprunghaft in den >osmerac wechseln (im folgenden Beispiel nach den ersten beiden Zeilen): Während der `desetarac $`$, der Vers der epischen, heldenbezogenen Volkslieder, ${ }^{27}$ einen gemäßigt sich fortentwickelnden, eher narrativen Sprach- und Bildfluss rhythmisiert, erzeugt der `osmerac eine - erneut - schnellere, hüpfende,

24 Zum ersten Mal veröffentlicht wurde der Text im Rahmen von Radičevićs erstem Gedichtband Pesme (1847). Vgl. zur anhaltenden Popularität Radičevićs z.B.: Ivanić: Pjesničko djelo Branka Radičevića, S. 201-244.

25 Radičević: Đački rastanak, S. 71 (»Kolo, kolo, rundherum, feenhaft, lebhaft, geflochten, gestrickt, verziert, gewürzt!«)

26 Vgl. Ivanić: Pjesničko djelo, S. 228f. Vgl. auch: Popović: Istorija srpske književnosti, S. 120.

27 Vgl. zur Metrik der volksepischen Literatur im südslawischen Raum: Lajić-Mihajlović: Vremenska dimenzija epskih pesama. 
durch die `Kolo<-Bilder zyklisch anmutende Klangtopographie, welche sich im Textverlauf schrittweise intensiviert:

Гледни само после ује сваке, гледни, брате, оне ноге лаке!

Та тек што се свирац чује, већ у колу с> поскакује.

Коло, коло, свирац свира, нога земљу не додира. »Ситно, брате, ијујују!« Момци чили подвикују: »Свирац свира, не да мира, а још више девојчице, њине очи и ножице!

$[\ldots]$

Ао, селе босонога, зла ти маја до зла Бога, не дала ти чарапица, ни лагани〉 папучица, да учиниш клепа клапа: за тобоме, душо, скапа'! ${ }^{28}$

Mit dem Metruswechsel parallelisiert sich hier ein gradueller Wechsel vom `Kolo< als Signifikat zum `Kolo< als Signifikant, indem der Text von der Darstellung eines Reigens zum Modus seiner Darstellung wechselt. Dieser Wechsel vollzieht sich indes nicht endgültig; die stark klangorientierten, zuweilen beinahe lautmalerischen Textstellen (»не дала ти чарапица, ни лагани' папучица, да учиниш клепа клапащ) werden immer wieder mit einer von außen gegebenen Darstellung der Tanzhandlung überlagert, sodass der Text die Spannung zwischen der Beschreibung des $>$ Kolo $<$ und seiner Ausagierung suspendiert. Das Verfahren der Aufhebung der Grenzen zwischen >Telling und `Showing , welches nicht zuletzt durch eine intensive Verflechtung von literarischen und musikalischen Funktionsprinzipien erwirkt wird, ist auch für die in Đački rastanak konstruierten Identitätsperspektiven symptomatisch.

Auf ähnliche Weise wie der erste >Kolo< ist auch der zweite in den Text eingebaut, der - die Forschung nennt ihn zuweilen »kolo (srpskih) junaka « ${ }^{29}$

28 Radičević: Đački rastanak, S. 63. („Schau nur jeder Tante nach, schau, Bruder, diese leichten Beine! Kaum dass der Musiker aufspielt, schon wird im kolo gesprungen. Kolo, kolo, der Musiker musiziert, das Bein berührt den Boden nicht. `Sachte, Bruder, ijujuju!^ Die kräftigen Jungen rufen: >Der Musiker musiziert, gibt keine Ruhe, und noch mehr die Mädchen, ihre Augen und Beinchen! [...] He, barfüßige Schwester, deine Mutter ist schrecklich böse, gab dir keine Strümpfchen, auch keine leichten Pantöffelchen, dass du ratsch-klatsch machst: Nach dir lechzet meine Seele.«)

29 Vgl. Dragutinović: Pesme Branka Radičevića, S. 57. (Die Kommentare von Dragutinović befinden sich im Fussnotenbereich. Dieser ist nicht nummeriert.) 
(»Reigen serbischer Helden«) oder »kolo bratstva« (»Reigen der Bruderschaft/ Brüderlichkeit « $)^{30}$ - aus der Perspektive der identitätstopographierenden Funktionalisierung dieser Figur besonders beachtenswert ist. Der auch hier erfolgende Rhythmuswechsel vom `deseterac in den >osmerac markiert erneut den Wechsel von einer eher linearen, Ortschaften und historische oder persönliche Bezugspersonen beschreibenden Erzählhandlung in eine klanggeleitete und sich eher räumlich statt zeitlich ausdehnenden Lautbewegung. Đački rastanak hat, wie das ganze Schaffen von Radičević, einen stark musikalischen Charakter. Diese Klanggebundenheit erreicht einen Höhepunkt in den beiden `Kolo , welche dominant über musikalische Prinzipien organisiert sind. Gleichzeitig bleibt auch der zweite Reigen nicht ohne inhaltliche und >realitätsbezogene` Referenzen - und gerade in der Verschmelzung von klang- und identitätstopographierenden Verfahren wird die Wirkung, welche dieses Poem zeitigte, nachvollziehbar: Es führt weg vom Eindruck der Konstruiertheit hin zu einer sinn- und klangverwebenden Natürlichkeit, in welcher sich individuelle und kollektive Wahrnehmung verflechten.

Popović stellte bei der Manuskriptuntersuchung fest, dass der zweite `Kolo< zwei Jahre nach dem Verfassen des Resttextes entstanden ist, und brachte dies in Verbindung mit einem konkreten historischen Ereignis dem Slawenball in Wien von 1846, nach dessen Vorbild Radičević diesen zweiten `Kolo< als tanzende südslawische Bruderschaft modelliert habe. ${ }^{31}$ Doch auch als poetische Topographierung eines historischen Ereignisses betrachtet, ist Radičevićs Text von einer doppelten Nähe gezeichnet; zur Volkskunst und ihren sprachlichen und inhaltlichen Perspektiven und Programmen einerseits ${ }^{32}$ und zu einer für die Romantik typischen individualisierten und formflexiblen Sprache und Wahrnehmung andererseits.

Bezüglich Aufbau und Integrationsstrategien funktioniert Radičevićs ,Kolo< zunächst ähnlich wie Štoos' Poziv u kolo ilirsko: Wie bei Štoos werden (nach dem Aufrufen verschiedener historischer und mythopoetischer südslavischer Heldenfiguren) eine Reihe von Regionen abgeschritten und zur Teilnahme im Reigen aufgefordert. Erneut sind es Regionen und nicht >Nationen $<$ - selbst die Serben und Kroaten werden als Bewohner ihrer Regionen und nicht als Volk oder Ethnie bezeichnet - >Srbijanci<, ’'Rvaćani<, statt etwa $>$ Srblji<, >Hrvati<:

Брже, браћо, амо, амо, да се скупа поиграмо!

31 Vgl. ebd.

32 Vgl. Barac: Geschichte der jugoslavischen Literaturen, S. 102; Popović: Istorija, S. 119; Ivanić: Pjesničko djelo, S. 230f. 
Србијанче, огњу живи,

Ко се теби још не диви!

'Рваћане, не од лане,

Од увек си ти без мане!

Ој, Босанче, стара славо,

Тврдо срце, тврда главо: ${ }^{33}$

Die Reihe wird fortgesetzt, wobei die weiteren Regionsbewohner (Ero, ${ }^{34}$ Sremac, Crnogorac, Dalmatinac, Dubrovčanin, Slavonac, Banaćanin, Bačvanin) mit » $\mathrm{Oj}$ « oder »Ao« aufgerufen werden, was wiederum den Eindruck des ausagierten `Kolo<-Modus verstärkt. Bevor die geopoetisch-reelle Ebene von einer abermals lautmalerischen und sich tänzerischen Motiven hingebenden Spielweise abgelöst wird, ist ein Argument für diesen >Reigen der Brüder eingeschoben: »'Ватите се кола тога, од вишњег је оно Бога! «5 Diese Gottgegebenheit des `Kolo< scheint indes in der Lakonie, in welcher sie gegeben ist, vor dem Hintergrund des sonst ausgedehnten Charakters des Textes als Argument ein wenig konstitutives Element zu bleiben; auch, da es sogleich wieder von einer klangorganisierten Topographie abgelöst wird, mit welcher es selbst klanglich kaum verbunden ist, während im Fortgang des Poems der Klang einer Zeile jeweils in den der nächsten Zeile süberzufließen`scheint:

Руком држи братац брата,

Близу срца њега 'вата:

свирац свира,

срце дира,

рука с' диже на посао,

да л' ће коме бити жао!

Нога лупа, диже пра',

наоколо свуда стра'!

Нога лака, срце здраво,

коло лети, коло ћаво,

поскочица, ћаволица,

што је 'тела, то и смела,

ал' је жеца одолела. ${ }^{36}$

Radičević imaginiert einen Tanz von Gleichen (Gleichgesinnten und durch die Kreisstruktur abermals: Gleichberechtigten), welcher eine aus-

Radičević: Đački rastanak, S. 71 (»Schneller, Brüder, hierher, hierher,/ lasst uns gemeinsam tanzen!/ Serbe, lebendiges Feuer,/ wer staunt nicht über dich!/ Kroate, nicht seit gestern,/ seit immer bist du ohne Mangel!/ He, Bosnier, alter Ruhm,/ Festes Herz, harter Kopf:«).

34 Gemeint sind die Hercergovci, vgl. Dragutinović: Pesme Branka Radičevića, S. 71.

35 Radičević: Đački rastanak, S. 73 (»Fasst euch zu diesem kolo, er ist von Gott, dem höchsten!«).

36 Radičević: Đački rastanak, S. 73. (»Mit der Hand fasst der Bruder seinen Bruder,/ nah an seinem Herz:/ Der Musiker musiziert,/ berührt das Herz,/ die Hand erhebt sich zur Arbeit,/ niemand wird es reuen!/ Das Bein trampelt, wirbelt Staub auf,/ rundherum herrscht Angst!/ Leichtes Bein, gesundes Herz,/ der Reigen fliegt, der Reigen des Teufels,/ das Reigen-Lied, das Teufelslied,/ was es wollte, hat's gemacht,/ selbst der Durst wird ausgehalten.«) 
gedehnte, aber innerlich diversifizierte südslawische Region umfasst; einen Tanz, der auf einer diskursiv-referentiellen Ebene die verschiedenen Regionen gerade als Bestandteile des Reigens hochleben lässt, der indes in erster Linie nicht über logische oder ethische `Argumentation ` und Aushandlung funktioniert, sondern über eine lautspielerische, klanglich verankerte Herleitung oder Abwicklung, worin das volkskulturelle Element (`osmerac^, Themen und Formulierungen aus der Volksepik u.ä.) auf scheinbar organische Art mit einer individualisierten Sprache und Weltsicht verschmilzt. Wieder ist es der Reigen, in dessen Licht die regionalen Einheiten als solche und zugleich als zusammengehörige wahrgenommen werden. Radičević kommt somit, was sein identitätstopographisches Werkzeug betrifft, nah an Verfahren der bereits betrachteten Texte heran, offenbart auch eine Nähe zu den frühen Perspektiven auf eine südslawische Zusammengehörigkeit (wie z.B. jene des Illyrismus, wenn er auch diesen Begriff selbst ablehnte). ${ }^{37}$ Đački rastanak, und darin besonders der zweite `Kolo‘, zeigt dabei geradezu idealtypisch ein Austarieren zwischen zentrifugalen (das Individuelle: Regionen, Figuren, Metriken etc.) und zentripetalen (das Allgemeine: übergeordneter, gemeinsamer Zusammenhang, Zusammenklang etc.) Kräften. Eindrücklich zeigt dieser Text aber nicht nur die in der folkloristischen >Kolo<-Kultur angelegte Parallelisierung von musikalischen und textlich-diskursiven Wirkungsprinzipien, sondern auch ihre gegenseitige Suspendierung und Steigerung in einem sich scheinbar aus sich selbst heraus fortentwickelnden Klangsystem, welches sich nicht nur in andere Texte Radičevićs übergießt, ${ }^{38}$ sondern auch von anderen Autoren der v.a. serbischen Romantik vielseitig weiterverarbeitet wird. ${ }^{39}$

\section{Unhintergehbar: Pluralität und Konstruktion}

Es lassen sich an der Schnittstelle von identitäts- und klangtopographierenden Praktiken, wie sie in der Figur des `Kolo als einem Beispiel der literarischen Aktualisierung von Folklore im Kontext der Romantik und/oder

37 Vgl. z.B. Radičević: Bezimena, wo Radičević den Begriff `Illyrien` als erfundenen und unnatürlichen bloßstellt.

38 So finden sich prominente Stellen von Đački rastanak in anderen seiner Texte wieder: "Dedu, dedu -/ Da zavedu/ Lako kolo/ naokolo.« (Radičević: Radost i žalost, S. 149) Oder: „Samo jedno još ne mogu:/ Da zapevam glasovito,/ Glasovito, silovito « (Radičević: Mini Karadžić u spomenicu, S. 150). Oder: „Čovek, žena, momak, deva,/ Jedno drugo opet vara.../ Brže, zlato, brže amo,/ Bolja sveta da delamo." (Radičević: Bezimena - Ludi Branko, S. 188)

39 Vgl. etwa die folgenden Texte: Jovanović Zmaj: Đačko kolo, S. 8-9; ders.: Aprilili li li li!, S. 209-214; Kostić: O proslavi Brankova »Đačkog rastanka«, S. 80-82. 
der Nationalen Wiedergeburt betrachtet wurden, drei verallgemeinernde Feststellungen zu Formen und Funktionen der kollektiven Identitätsdiskurse dieser Zeit machen:

Die erste Feststellung betrifft die offensichtliche Tendenz, Identitätsräume in der Zeit als plurale, geschichtete und differenzierende zu topographieren. Zweifelsohne ist die Figur des Reigens hier nur eine unter vielen; andere Volks-Figuren oder nationale Semiotiken mögen zudem weniger intensiv in diese Richtung zeigen. Auch entzieht sich die Volkskultur in dieser Phase noch weitgehend einer homogenisierenden Nationalisierung von Kultur und Literatur (und tut es letztlich auch über die Romantik hinaus). Dennoch: Es finden sich auch im weiteren, gesamteuropäischen Kontext romantischer Volksdiskurse ähnliche Positionen, die Kultur als ein Konzert vieler verschiedener Stimmen (Volkssprachen, Volksliteraturen) konzipieren, die erst im Chor ihren wahren Klang entfalten. Nicht von ungefähr ist dies die Zeit blühender (pan)slawischer, (indo)germanischer und weiterer sprachlich-kultureller kosmopolitischer Gemeinschafts-Konzepte, welche der ebenso zentralen Volksindividualität konstitutiv zur Seite stehen. Denn erst im Vergleich mit anderen wird eine Entität - hier v.a. eine Region - zur Individualität. Dass die hier betrachteten Adaptionen des `Kolo auch pragmatisch-geopolitische Tendenzen der Zeit widerspiegeln - die Annahme der Notwendigkeit des Zusammenschlusses in Anbetracht der Übermacht der politisch-kulturellen Großkomplexe Ungarns, Habsburgs und des Osmanischen Reiches -, zeugt davon, wie geopolitische und geopoetische Strategien ineinanderfließen, wofür nicht zuletzt die Reigen-Figur in ihrer vielschichtigen Bedeutungsstruktur einen passenden Rahmen bietet.

Die zweite Feststellung betrifft den unhintergehbaren Konstruktionscharakter, den diese Klang- und Identitätstopographien kaum verbergen. Gegenüber der in allen Texten identisch gesetzten Region als `natürlicher kleinster Einheit geopoetischer/ geopolitischer Identifikation weisen die erweiterten, ausgedehnten Integrationsräume verschiedentlich auf ihren eigenen radikal imaginären und teilweise auch ephemeren Charakter hin. Zwar verbindet sich gerade mit der aus der >ursprünglichen Volkskultur stammenden Reigen-Figur ein Anspruch auf Authentizität - nicht zuletzt auch über eine im Musikalischen enthaltene Ahnung von Vollkommenheit und Harmonie. ${ }^{40}$ Dies steigert sich in den drei Texten graduell und findet in Đački rastanak einen Höhepunkt - auch zu einem Zeitpunkt, als sich (pan)slawische Visionen besonders verdichteten, bevor die Ereignisse nach

40 Vgl. hierzu Jauß’ Konzept der »Ahnung der Vollkommenheit«, welches dieser aus Isers >Imaginärem ‘ entwickelt: Jauß: Die kommunikative Funktion des Fiktiven, S. 304. 
1848 die Hoffnungen der `kleineren` Völker nach föderativen Modellen im europäischen (z.B. Habsburgischen) Zusammenleben lähmten. Doch widerspiegeln die verschiedenen Argumentationsverläufe für die teilweise komplexe Zusammenfügung, wie auch die Sichtbarmachung der einzelnen Integrationsobjekte und die Reflexion deren verschiedener Relationen, ein klares Bewusstsein nicht nur für das `Gemachte dieser Identitätstopographien, sondern auch für das Spielerische, das ihnen doppelt eingeschrieben ist, da es natürlich auch die Tanzfigur prominent kennzeichnet. Die in der Forschung kaum bestrittene Konzipierung der frühen (süd)osteuropäischen Nationsbewegungen als kulturelle ${ }^{41}{ }^{4}$ spiegelt sich hier in einer Spielfigur, welche sich indes gleichzeitig intensiv mit geopolitischen Strukturen auseinandersetzt. Dies führt zur letzten Feststellung:

Die >Kolo<-Figur stellt vehement die Frage der (De-)Hierarchisierung pluraler Strukturen - und dies enthält für den Kontext der Nationalismusforschung eine wichtige Erkenntnis. Unbestreitbar steht der Reigen für eine egalitäre plurale Identitätstopographie: Im Kreistanz findet die Suspension zentrifugaler und zentripetaler Kräfte statt und ist die unauflösbare Opposition von Individualität und Totalität (mindestens vorübergehend) harmonisch austariert. Die plurale Struktur ist ebenso charakteristisch für den imperialen Raum, welcher die südslawischen Regionen zu dieser Zeit prägt (eine Pluralität von Sprachen, Völkern, Kulturen und von verschiedenen inneren Grenzziehungen, Identifizierungsmaßstäben usw.), wobei die imperiale Pluralität allerdings stets eine hierarchische ist. Eine Grundimplikation nationaler Narrative lautet deshalb, dass sich gerade aus der hierarchischen imperialen Pluralität die nationalen Entitäten befreien und dass sich in diesem Einigungsprozess ahierarchische, homogene Räume bilden mussten. Die Identitätstopographien, auf welche die literarisierte Figur des >Kolo< ein Schlaglicht wirft, betonen somit ein häufig ausgeblendetes Moment: Es handelt sich hier um Imaginationen kollektiver Identitätstopographien, die eindeutig die Intention der Dehierarchisierung offenbaren, indes aber nicht auf Pluralität verzichten - auch dann, wenn regionale (!) Individualität gesetzt und gefeiert wird. Pluralität scheint gerade die Voraussetzung für die Anerkennung von Individualität zu bilden. In diesem Sinne muss der imperiale Raum in seiner hierarchisch verzerrten Pluralität nicht nur als Katalysator für eine Dehierarchisierung und Egalisierung im Sinne der Implementierung von eindeutig voneinander abgetrennten und innerlich homogenen nationalen Einheiten betrachtet werden, sondern auch als Ausgangspunkt egalitärer Konzepte für plurale Gesellschaften. Der 
verflechtende Übergang zwischen verschiedenen medialen Wirkprinzipien der Volkskultur, Volksmusik und Literatur bietet dazu eine ideale Plattform.

Wenn Caroline Emcke, Preisträgerin des Friedenspreises des deutschen Buchhandels 2016, zu Recht kritisiert, dass Gründe, warum eine homogene Kultur oder Nation für einen modernen Staat grundsätzlich besser sein sollte als eine heterogene, selten genannt werden ${ }^{42}$ und betont, dass »Pluralität in einer Gesellschaft [...] nicht den Verlust der individuellen (oder kollektiven) Freiheit [bedeute], sondern [diese] erst [garantiere] «, ${ }^{43}$ dann kann diese heute leicht zu bejahende Position nicht unmittelbar auf das imperiale, mannigfaltig hierarchisierte 19. Jahrhundert übertragen werden. Die betrachteten literarischen $>$ Kolo<-Bearbeitungen können in ihren Gesellschaftstopographierungen dennoch zeigen, dass Pluralität für sie grundlegend und konstitutiv ist, wenn sie auch ausgehandelt werden muss - nicht zuletzt gerade auch im Kontext der Volkskultur, in welcher sich individuell-lokale und allgemein-globale Zeichenprozesse immer schon durchkreuzten. Wenn diese Gedichte kollektive Identitäten jenseits des Nationalen topographieren, dann tun sie dies nicht nur auf einer programmatischen Ebene der Topographierung von trans- und supranationalen Gemeinschaftsperspektiven, sondern auch auf einer musikalischen Ebene, indem die Volkskultur sich - über ihr eigene dynamische Klangprozesse - einer vereindeutigend domestizierenden Nationalisierung entzieht. Besonders in der Verschmelzung und gegenseitigen Steigerung von musikalischen und literarischen Strategien erzeugen diese Gedichte so eine hohe Flexibilisierung und innere Spannung von Identität.

\section{Literaturverzeichnis}

Barac, Antun: Geschichte der jugoslavischen Literaturen von den Anfängen bis zur Gegenwart. Aus dem Serbokroat. übertr., bearb. u. hrsg. von Rolf-Dieter Kluge. Wiesbaden: Otto Harrassowitz 1977.

Becking, Gustav: Der musikalische Bau des Montenegrinischen Volksepos. La Hague: Harlem 1933.

Coha, Suzana: Medij, kultura, nacija. Poetika i politika Gajeve Danice. Zagreb: Hrvatska sveučilišna naklada 2015.

Dragutinović, M. K.: Branko Radičević. In: Pesme Branka Radičevića. Knjiga prva. Hg. ders. Beograd: Državna štamparija kraljevine Srbije 1903, S. III-XXVI.

Drašković, Janko: Poskočnica. In: Hrvatski narodni preporod I. Ilirska knjiga. Hg. Jakša Ravlić (Pet stoljeća hrvatske književnosti, knjiga 28). Zagreb: Matica hrvatska u. Zora 1965. 
Dubinskas, Frank A.: Performing Slavonian Folklore. The Politics of Reminiscence and Recreating the Past (Yugoslavia). (Unpublizierte Dissertation.) Stanford University 1983.

Emcke, Caroline: Gegen den Hass. Essay. Frankfurt/M.: Fischer 2016.

Frank, Susi K.: Geokulturologie - Geopoetik. Definitions- und Abgrenzungsvorschläge. In: Geopoetiken. Geographische Entwürfe in den mittel- und osteuropäischen Literaturen. Hgg. Magdalena Marszalek, Sylvia Sasse. Berlin: de Gruyter 2010, S. 19-42.

Gaj, Ljudevit: Naš narod. »Danicza Horvatzka, Slavonzka y Dalmatinzka« 34 (1835), S. 234-236.

Ivanić, Dušan: Pjesničko djelo Branka Radičevića. In: ders.: Ka genezi srpske poezije (pregledi i studije). Beograd: Akademija 2011, S. 201-244.

Jauß, Hans Robert: Die kommunikative Funktion des Fiktiven. In: ders.: Ästhetische Erfahrung und literarische Hermeneutik. Frankfurt/M.: Suhrkamp 1991, S. 293-262.

Jovičević, Tatjana: Prostori srpskog predromantizma. »Naučni sastanak slavista u Vukove dane. Beograd, 12.-14. IX. 2012. Razvojni tokovi srpske poezije« 42.2 (2013), S. 491-500.

Kostić, Laza: O proslavi Brankova Đačkog rastanka. In: ders.: Pesme. Bd. 3. Hg. Vladimir Otović. Novi Sad: Matica Srpska 1991, S. 80-82.

Lacko Vidulić, Svjetlan: Jugoslawische Literatur. Kurzer Abriss zur langen Geschichte eines produktiven Phantoms. In: Traumata der Transition. Erfahrung und Reflexion des jugoslawischen Zerfalls. Hgg. Boris Previšić, Svjetlan Lacko Vidulić. Tübingen: Francke 2015, S. 161-182.

Lajić-Mihajlović, Danka: Vremenska dimenzija epskih pesama. »Muzikologija« 6 (2006), S. 343-336.

Lauer, Reinhard: Volksepik und Kunstepik - Syntheseversuche in der serbischen Literatur zwischen 1790 und 1830. In: Jugoslawien - Integrationsprobleme in Geschichte und Gegenwart. Beiträge des Südosteuropa-Arbeitskreises der Deutschen Forschungsgemeinschaft zum V. Internationalen Südosteuropa-Kongress der Association internationale d'études du Sud-Est Européen, Belgrad, 11.-17. September 1984. Hg. Klaus-Detlev Grothusen. Göttingen: Vandenhoeck \& Ruprecht, 1984, S. 196-219.

Merchiers, Ingrid: Cultural Nationalism in the South Slav Habsburg Lands in the Early Nineteenth Century. The Scholarly Network of Jernej Kopitar (1780-1844). München: Otto Sagner 2007.

Mladenović, Olivera: \Kolo< u južnih Slovena. Beograd: Prosveta (Etnografski institut: Posebna izdanja: knjiga 14) 1973.

Popović, Miodrag: Istorija srpske književnosti. Knjiga druga. Romantizam 2. Beograd: Zavod za udžbenike i nastavna sredstva 1985.

Radičević, Branko: Bezimena - Ludi Branko. In: ders.: Rukovet. Hg. Milan Dedinac (Srpska književnost u sto knjiga, knjiga 23). Novi Sad: Matica Srpska; Beograd: Srpska književna zadruga 1963, S. 169-208.

Radičević, Branko: Bezimena. In: Pesme Branka Radičevića. Knjiga prva. Hg. M. K. Dragutinović. Beograd: Državna štamparija kraljevine Srbije 1903, S. 152-153.

Radičević, Branko: Đački rastanak. In: Pesme Branka Radičevića. Knjiga prva. Hg. M. K. Dragutinović. Beograd: Državna štamparija kraljevine Srbije 1903, S. 57-82.

Radičević, Branko: Mini Karadžić u spomenicu. In: ders.: Rukovet. Hg. Milan Dedinac (Srpska književnost u sto knjiga, knjiga 23). Novi Sad: Matica Srpska; Beograd: Srpska književna zadruga 1963, S. 150.

Radičević, Branko: Radost i žalost. In: ders.: Rukovet. Hg. Milan Dedinac (Srpska književnost u sto knjiga, knjiga 23). Novi Sad: Matica Srpska; Beograd: Srpska književna zadruga 1963, S. 144-149. 
Ravlić, Jakša: Janko Drašković. In: Hrvatski narodni preporod I. Ilirska knjiga (Pet stoljeća hrvatske književnosti, knjiga 28). Hg. Jakša Ravlić. Zagreb: Matica hrvatska u. Zora 1965, S. 87-91.

Rječnik hrvatskoga ili srpskoga jezika. Bd. VI. Zagreb: JAZU 1898-1903.

Rizvić, Muhsin: Interpretacije iz romantizma I. Sarajevo: Svjetlost 1976.

Rizvić, Muhsin: Interpretacije iz romantizma II. Sarajevo: Svjetlost 1984.

Shay, Anthony: LADO, the State Ensemble of Croatian Folk Dances and Songs: Icon of Croatian Identity. In: The Oxford Handbook of Dance and Ethnicity. Hgg. Anthony Shay, Barbara Sellers-Young. Oxford: Oxford University Press 2016, S. 256-278. (Online Publikation: S. 1-29).

Štoos, Pavao: Kip domovine vu početku leta 1831. In: Hrvatski narodni preporod I. Ilirska knjiga (Pet stoljeća hrvatske književnosti, knjiga 28). Hg. Jakša Ravlić. Zagreb: Matica hrvatska u. Zora 1965, S. 245-250.

Štoos, Pavao: Poziv u kolo ilirsko. In: Hrvatski narodni preporod I. Ilirska knjiga (Pet stoljeća hrvatske književnosti, knjiga 28). Hg. Jakša Ravlić. Zagreb: Matica hrvatska u. Zora 1965, S. 251-253.

Živančević, Milorad: Tipologija hrvatskog i srpskog romantizma. In: Komparativno proučavanje jugoslavenskih književnosti. Drugi zbornik radova. Hg. Franjo Grčević. Zagreb: Zavod za znanost o književnosti filozofskog fakulteta 1985, S. 30-33.

Zmaj, Jovan Jovanović: Đačko kolo. In: ders.: Pesme. Lirske, misaone, rodoljubive. Hg. Boško Petrović. Novi Sad: Matica Srpska 1973, S. 8-9.

Zmaj, Jovan Jovanović: Aprilili li li li! In: Odabrana dela Jovana Jovanovića Zmaja. Bd. 5: Političke i satiričke pesme. Hgg. Mladen Leskovac, Živan Milisavac. Novi Sad: Matica srpska 1979, S. 209-214. 